\title{
Zebrafish: an emerging real-time model system to study Alzheimer's disease and neurospecific drug discovery
}

Suraiya Saleem ${ }^{1}$ and Rajaretinam Rajesh Kannan ${ }^{1}$

\begin{abstract}
Zebrafish (Danio rerio) is emerging as an increasingly successful model for translational research on human neurological disorders. In this review, we appraise the high degree of neurological and behavioural resemblance of zebrafish with humans. It is highly validated as a powerful vertebrate model for investigating human neurodegenerative diseases. The neuroanatomic and neurochemical pathways of zebrafish brain exhibit a profound resemblance with the human brain. Physiological, emotional and social behavioural pattern similarities between them have also been well established. Interestingly, zebrafish models have been used successfully to simulate the pathology of Alzheimer's disease (AD) as well as Tauopathy. Their relatively simple nervous system and the optical transparency of the embryos permit real-time neurological imaging. Here, we further elaborate on the use of recent real-time imaging techniques to obtain vital insights into the neurodegeneration that occurs in AD. Zebrafish is adeptly suitable for $\mathrm{Ca}^{2+}$ imaging, which provides a better understanding of neuronal activity and axonal dystrophy in a non-invasive manner. Three-dimensional imaging in zebrafish is a rapidly evolving technique, which allows the visualisation of the whole organism for an elaborate in vivo functional and neurophysiological analysis in disease condition. Suitability to highthroughput screening and similarity with humans makes zebrafish an excellent model for screening neurospecific compounds. Thus, the zebrafish model can be pivotal in bridging the gap from the bench to the bedside. This fish is becoming an increasingly successful model to understand AD with further scope for investigation in neurodevelopment and neurodegeneration, which promises exciting research opportunities in the future.
\end{abstract}

\section{Facts}

- Zebrafish can be used as a model to study various disease pathologies in Alzheimer's disease.

- Laser axotomy coupled with time-lapse imaging and 3D imaging reveal interesting facts about degeneration/regeneration in Zebrafish larvae.

- New approaches to treat Alzheimer's disease can be further unearthed with this model.

Correspondence: Rajaretinam Rajesh. Kannan (rajeshkannan. mnru@sathyabama.ac.in) (rajeshnbt12@gmail.com)

${ }^{1}$ Neuroscience Lab, Molecular and Nanomedicine Research Unit, Centre for Nanoscience and Nanotechnology, School of Bio and Chemical Engineering, Sathyabama Institute of Science and Technology, (Deemed to be University), Jeppiaar Nagar, Rajiv Gandhi Salai, Chennai 600119 Tamil Nadu, India Edited by I. Amelio

\section{Open questions}

- How does zebrafish serve as a model for understanding Alzheimer's disease?

- Can real-time imaging in zebrafish address the major breakthroughs in the field of Alzheimer's research?

- Can zebrafish merge the gap between neurospecific drug discovery and clinical research?

\section{Introduction: zebrafish is emerging as a robust model for study of human neurodegeneration}

The zebrafish (Danio rerio) is a prominent vertebrate model system for comprehensive analysis of the unique functions of genes along with their signalling pathways during development and neurodegeneration ${ }^{1}$. Such

\section{(c) 2018 The Author(s)}

(c) (i) Open Access This article is licensed under a Creative Commons Attribution 4.0 International License, which permits use, sharing, adaptation, distribution and reproduction in any medium or format, as long as you give appropriate credit to the original author(s) and the source, provide a link to the Creative Commons license, and indicate if changes were made. The images or other third party material in this article are included in the article's Creative Commons license, unless indicated otherwise in a credit line to the material. If material is not included in the article's Creative Commons license and your intended use is not permitted by statutory regulation or exceeds the permitted use, you will need to obtain permission directly from the copyright holder. To view a copy of this license, visit http://creativecommons.org/licenses/by/4.0/. 


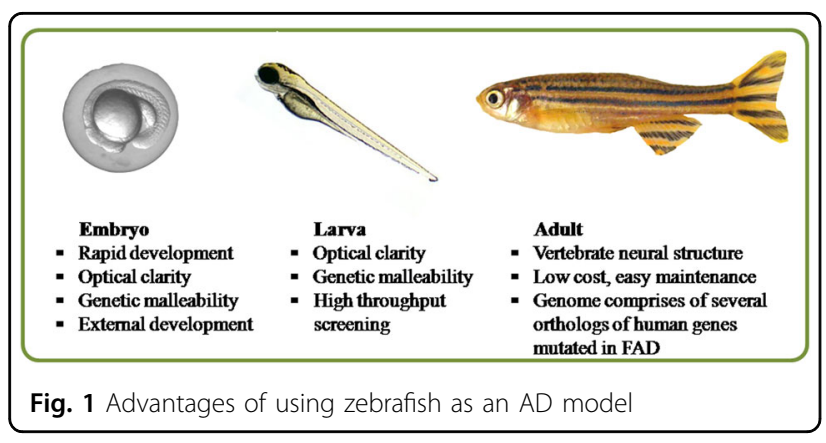

studies have been possible as the zebrafish possesses several distinct advantages over other vertebrate models (Fig. 1).

- Owing to the simplicity of their natural habitat, it is much easier to maintain them in a laboratory than to simulate the conditions essential for mammals. Thus, zebrafish can be grown in a cost-effective manner. Their short generation times of 3-5 months enhances the rate of experimental progress ${ }^{2}$.

- They possess external fertilisation and their development pattern facilitates the observation and experimental manipulation of the embryos. Moreover, they have large clutch size varying between 200 and 300 per fish, which ensures a ready supply of animals for research work.

- One of the most unique advantages of the zebrafish is the unrivalled optical clarity of the embryos, allowing visualisation of individual genes (fluorescently labelled or dyed) throughout the developmental process using non-invasive imaging techniques ${ }^{3-8}$. This transparency of the embryo also helps in genetic manipulations.

- Owing to the small size of the larvae, highthroughput screening of neuroactive compounds can be easily performed.

- It is very easy to introduce transient manipulation of gene activities and their subsequent examination in a normal cellular environment ${ }^{9,10}$ (Fig. 2). The embryos are quite malleable to genetic manipulation by morpholino antisense oligonucleotide, mRNAs, transgenes and genome editing techniques like CRISPR-Cas9, TALENS ${ }^{11-13}$.

- The zebrafish possess a vertebrate neural structural organisation and their genome has several gene orthologs similar to those mutated in human Familial Alzheimer's disease (FAD). Very recently in an interesting study, scientists have upgraded the web tool for analysing zebrafish genes using gene ontology as the entire zebrafish genome has been sequenced $^{14}$.
Therefore, zebrafish pose a better model system than rodents as they allow in vivo analysis without disturbing the physiological milieu of the disease.

\section{$A D$ and pathogenesis}

Alzheimer's disease (AD) is a progressive neurodegenerative disease. It is the most prevalent form of dementia in the world affecting almost 47 million people worldwide (Alzheimer's Association) $^{15}$. The number of Alzheimer's patients is projected to reach 82 million globally by 2030 , and the number is expected to rise to 152 million by 2050 of which Asia-Pacific alone shall contribute 71 million cases. The total cost for AD is estimated to be $\$ 183$ billion, which might rise up to $\$ 1.1$ trillion by $2050^{16}$. The two main pathological hallmarks of the disease include $A \beta$ plaques and neurofibrillary tangles ${ }^{17}$. Other clinical features include depression, hallucinations, speech impairment, motor disabilities and aggressive behaviour ${ }^{18}$. Though extensive research has been done, yet, early diagnosis of $\mathrm{AD}$ is still not possible ${ }^{19}$. The latter stages of AD include significant neuronal loss in specific regions of the brain, ultimately leading to shrinkage of the total volume of the brain ${ }^{20-22}$. AD can be categorised into two main types, familial AD (FAD) and sporadic AD (SAD) ${ }^{23}$.

FAD shows an autosomal dominant inheritance and is usually caused by mutations occurring mainly in three genes, Amyloid precursor protein (APP), Presenilin 1 (PSEN1) and Presenilin 2 (PSEN 2) ${ }^{23,24}$. FAD accounts for only $\sim 1-5 \%$ cases of $\mathrm{AD}$, whereas the rest is attributed by $\mathrm{SAD}^{25}$. SAD is attributed mainly by a combination of environmental risk factors and genetic susceptibility. Reports suggest a functional role of Apolipoprotein $\mathrm{E}$ (ApoE) phenotype in the late-onset $\mathrm{AD}^{26}, \varepsilon 4$ allele being the major risk factor for $\mathrm{AD}$, whereas $\varepsilon 2$ allele is protective ${ }^{27,28}$.

The presence of $A \beta$ plaques in the brain led to the origin of the $A \beta$ hypothesis ${ }^{29}$. It suggests the pivotal role of $A \beta$ in initiating and triggering the pathology of the disease including inflammation and oxidative stress ${ }^{30}$. For decades, $A \beta$ deposition and aggregation have been treated as the primary mechanisms underlying the disease pathology. Though $\mathrm{A} \beta$ hypothesis is central to the disease, scientists, however, have propounded several other hypotheses ${ }^{31,32}$. Among them, the earliest proposed was the cholinergic hypothesis. ${ }^{33}$ Decrease in the cholinergic transmission in $\mathrm{AD}$ is responsible for the abnormalities in the cognitive and functional domains of $\mathrm{AD}$ patients. However, it is now clear, that cholinergic dysfunction can cause cognitive impairment only through indirect mode ${ }^{33}$. Another most prevalent hypothesis is the tangles hypothesis. ${ }^{34}$ A better correlation exists between presence of tangles and status of the disease progression; however, the amyloid hypothesis holds as it has been noticed that 


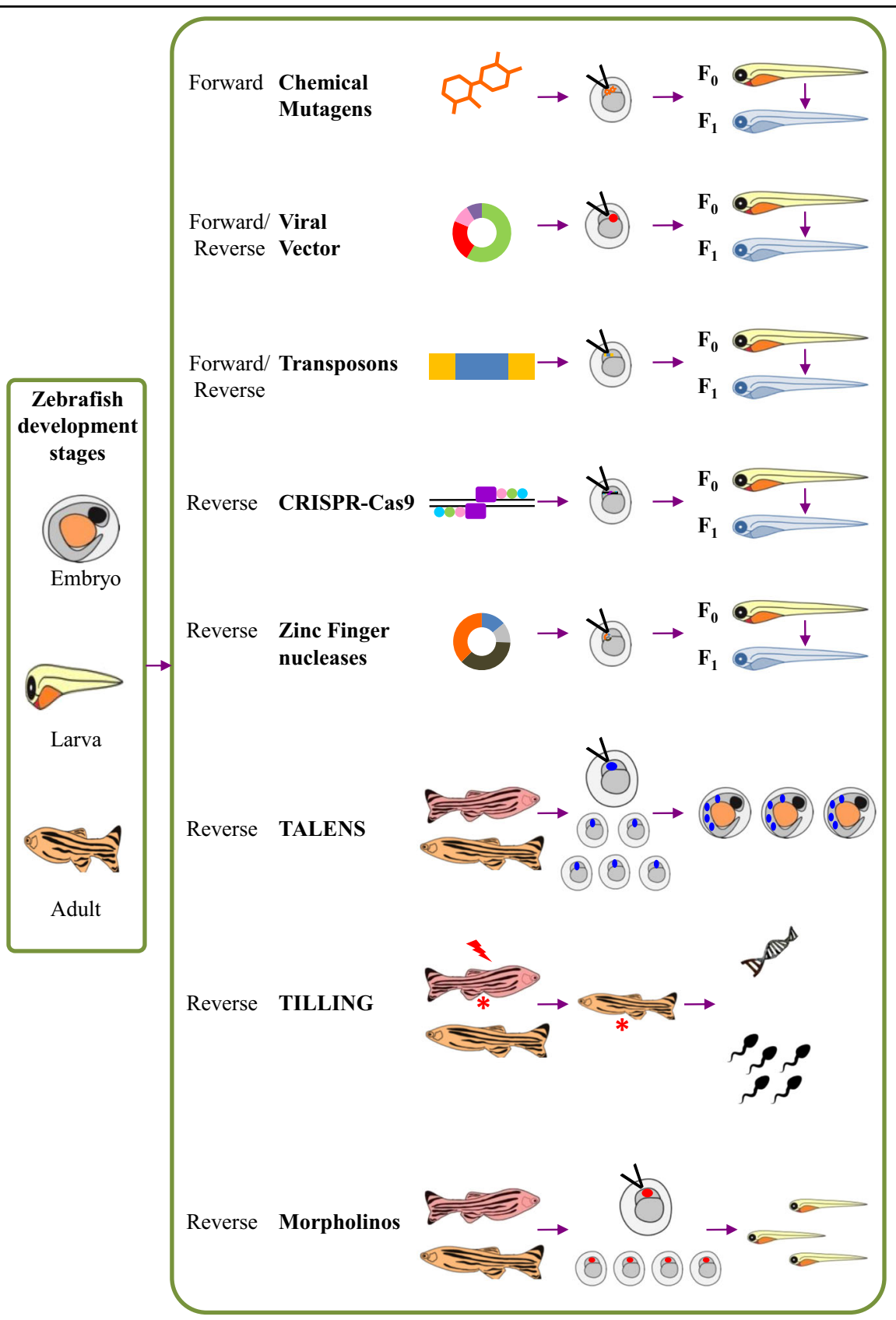

Fig. 2 Possible genetic manipulations in zebrafish: 'forward genetic' tools exist to create random mutations in the zebrafish genome. Several 'reverse genetic' methods are also in use to identify and characterise zebrafish genes of interest either by overexpression or by knocking it out. For inducing mutations researchers have used chemical mutagens like Ethyl-Nitroso Urea, viral vectors, transposon-based mutagenesis by conditional "gene trapping" and "gene breaking", zinc finger nucleases, and the more recent one being, clustered regularly interspaced short palindromic repeats (CRISPR-Cas9) systems, which provide the advantage of gene manipulation with ease and high efficiency, eliminating any unwanted off-target effect. Morpholinos, based on the antisense oligonucleotide gene knockdown technique, are the most regularly used reverse genetic tool for gene manipulation in zebrafish. They are designed in such a way that they bind to specific locations on the transcripts from genes of interest. The mode of action of morpholino can be by either blocking translation or interfering with the proper splicing of the exons. Targeting Induced Local Lesions in Genomes' (TILLING) method, has also been successfully adapted to zebrafish. Most recently the Transcription Activator-Like Effector Nucleases (TALENS) system is the most potent system for targeting genes in the zebrafish model

mutations in Tau do not result in plaque deposition. Among other hypotheses, the calcium hypothesis explains how the activation of the amyloidogenic pathway regulates the calcium signalling in the neurons to affect $\operatorname{cognition}^{35,36}$. However, the relation between dysregulated calcium signalling, aging and cognitive decline are 
still not clear ${ }^{36}$. The mitochondrial hypothesis suggests that the mitochondria plays a major role for the production of reactive oxygen species and subsequent neurodegeneration ${ }^{37}$. The complete link between mitochondria and the disease is yet to be established. Hence, a better understanding of the various hypotheses in $\mathrm{AD}$ will definitely direct our approach for better treatment strategies of the disease.

\section{Zebrafish as an AD model}

\section{Neuroanatomical similarity}

Research shows a high conservation between zebrafish and human brain organisation ${ }^{38}$. A great degree of similarity between their neuroanatomic ${ }^{39-41}$ and neurochemical pathways ${ }^{42}$ are reported. The medial, dorsal and lateral pallium of the zebrafish are similar to the amygdala $^{43}$, isocortex ${ }^{44}$ and hippocampus ${ }^{45,46}$ in other vertebrates, respectively. The zebrafish encephalon comprises of the forebrain, mid brain and hind brain, (diencephalon, telencephalon and cerebellum). Similar to mammalian brain, the zebrafish brain harbours the main excitatory glutamatergic and inhibitory GABAergic neurotransmitter circuits ${ }^{47}$ along with the presence of muscarine cholinergic receptors ${ }^{48}$. Besides, they possess GABA, glutamate, serotonin, dopamine, histamine, acetylcholine neurotransmitters ${ }^{49}$, enzymes of synthesis and for metabolism ${ }^{50,51}$. Similarity exists even at the cellular level, as the cell types astrocytes ${ }^{52}$, microglia ${ }^{53}$, oligodendrocytes ${ }^{54}$, cerebellar Purkinje cells $s^{55}$, myelin ${ }^{56}$ and motor neurons ${ }^{57}$ are found similar to human cells. Further studies on the neuronal patterns in the spinal cord of adult zebrafish, neural differentiation and development of spinal network establish their similarity to higher order vertebrates $^{58-60}$.

\section{Behavioural similarity}

Several anthropomorphic assays have been performed to depict similar behavioural pattern between zebrafish and humans, which implicates a conserved behavioural mechanism and circuitry paradigm of both systems. Researchers have employed the zebrafish behavioural pattern to study physiological behaviour like feeding ${ }^{61-63}$, learning ${ }^{64}$, hearing ${ }^{65}$, vision ${ }^{66}$, touch ${ }^{67-69}$ and emotions like fear $^{70-72}$, pain $^{73}$, helplessness ${ }^{74}$, courtship ${ }^{75}$, social interactions $^{69,76,77}$, anxiety ${ }^{78}$ and decision making ${ }^{79}$. Further, reports indicate similarity between expression patterns and axonal projections of hypocretin/orexin neurons of larval zebrafish and humans ${ }^{80}$. Interestingly, because of the high degree of behavioural similarity between zebrafish and humans; researchers have also employed the use of circadian rhythm in zebrafish locomotor activity to understand the mechanism, which can regulate sleep in humans ${ }^{80-83}$. Sleep behaviour pattern has been studied in the zebrafish and has been simulated with sleep-like state in mammals. This study shows that the rest phase in zebrafish and the behavioural manifestations of sleep in mammals exhibit considerable fundamental similarities. They further report that the zebrafish exercise homoeostatic control over rest behaviour which is regulated by the circadian rhythm, features similar to that of mammals ${ }^{84}$. Disruptions in the circadian rhythm in $\mathrm{AD}$ have been reported by several groups ${ }^{85-90}$. Although a link between circadian cycle and AD is clearly implicated, a proper mechanistic explanation connecting them is still lacking. The interactions among the proteins involved in maintaining circadian rhythm in the zebrafish is quite similar to those observed in the mammals ${ }^{91-94}$. Apart from this, the cholinergic neurotransmitter system modulates drug induced reward activity in the zebrafish making it compatible to study the neurobiology of addiction. This establishes the zebrafish as a robust model for studying the biology of behaviour in vertebrates $^{95}$.

\section{Pathophysiological resemblance}

Several zebrafish models have been established by placing $A \beta$ central to the disease pathology to simulate $A D$. A group of researchers suggest that higher levels of $A \beta$ monomers can stimulate angiogenic sprouting in the developing zebrafish hind brain ${ }^{96}$. Quite interestingly, another group found both APP and A $\beta$-deficient larvae displayed cerebrovascular defects. Interestingly, these anomalies could be reversed by treating the embryos with human $A \beta_{1-42}$ peptide. However, there was no effect when they were treated with $\mathrm{p} 3$ (the shorter APP cleavage product $)^{97}$. This finding brought to light the significant cerebrovascular growth promoting function of $A \beta$. Further, the embryos treated with $2.5 \mu \mathrm{M}$ of $\mathrm{A} \beta_{1-40}$ led to abnormal vasculature development and cell death ${ }^{98}$.

Besides the $A \beta$ model, research has also focussed on the generation of zebrafish models with Tauopathy ${ }^{99}$. Cytoskeletal disruption occurred on expressing frontotemporal dementia with Parkinsonism linked to chromosome 17, a mutant form of human Tau in the neurons of the zebrafish, which resembled the neurofibrillary tangles observed in $A D^{100,101}$. Another group expressed mutated form of the human $\tau$ protein in the zebrafish neurons which disrupted the cytoskeletal structure ${ }^{101}$. Although removal of exon2 from Enolase GFP-transgenic zebrafish and its replacement with complementary DNA that encoded for the four-repeat isoform of the human Tau resulted in eight times overexpression of Tau in the zebrafish brain compared with normal human brain. The overexpressed Tau localised to axons and resembled neurofibrillary tangles ${ }^{102}$. These reports exemplify the use of zebrafish as a model for AD. 


\section{Zebrafish as a neuropharmacological model}

Researchers have checked non-associative learning in the zebrafish larvae based on cognitive and behavioural responses of $\mathrm{AD}$. Seven days post fertilisation (dpf) larvae were exposed to a series of acoustic stimuli, to which the larvae displayed significant reduction of startle response ${ }^{103}$. Another group injected $A \beta_{1-42}$ into the hind brain ventricle of $24 \mathrm{~h}$ post fertilisation (hpf) zebrafish embryos. They observed significant cognitive deficits in the embryos with increased Tau phosphorylation in target residues of GSK-3 $\beta$ in the $5 \mathrm{dpf}$ larvae ${ }^{104}$. Zebrafish embryos exposed to Trimethyltin chloride (TMT) exhibited neurobehavioural toxicity, specifically, apoptosis in the tail, modulations in photomotor response and frequency of tail flexion ${ }^{105}$. Most recently, another pharmacologic model of AD has been developed by adding okadaic acid $^{106}$. Both $A \beta$ plaques and phosphorylarion of Tau have been found to increase with increasing concentrations of okadaic acid. Learning and memory deficits have also been observed in these fish ${ }^{106}$. Zebrafish treated with Aluminium in an acid environment displayed behaviour with $\mathrm{AD}$-like condition wherein their locomotor activity and learning ability got abrogated ${ }^{107}$. Furthermore, it has been reported that intraventricular injection of $A \beta_{1-42}$ in the embryonic brain leads to memory loss and cognitive deficits along with increased Tau phosphorylation ${ }^{104,108}$. The zebrafish is therefore emerging as a powerful model for research in the field of neuropharmacology.

\section{Zebrafish as neurogenetic model}

Researchers have unravelled the role of APP in FAD using the zebrafish model, whereby, APP knockdown zebrafish displayed defective convergent-extension movements with reduced body length and short curled tail. They showed that Swedish mutant APP is unable to overcome the developmental defects unlike the wild type $\mathrm{APP}^{109,110}$. In addition, it has been shown that the Sortilin-Related Receptor (SORL1)-dependent switch can divert APP from the late endosomal pathway. This sequesters the APP into the endosomes, thus preventing the formation of $A \beta^{111,112}$. Another group has showed that the wild type Psen1 in the zebrafish facilitates anomalous $A \beta_{1-42}$ secretion similar to mutations associated with $\mathrm{FAD}^{113}$. Zebrafish embryos injected with morpholinos, which block Psen1 translation are viable but show p53-dependent apoptotic death of neurons ${ }^{114-117}$. A unique function of the Psen1 has come to light through studies in a mutant zebrafish lacking Psen 1 activity. These mutant fish are viable and reveal the regulation of histaminergic neuronal development by Psen1 in the fish ${ }^{118}$. Unlike Psen1, loss of Psen2 expression hinders the synthesis of dorsal longitudinal ascending interneurons from the spinal cord during the development of zebrafish larvae ${ }^{119}$. In an interesting study, the scientists report the pathological role of a new truncated isoform, PS2V of Psen2 and its implication in neurodegenerative diseases ${ }^{117}$. Research has focussed on the $\beta$ secretase as well, whereas Bace1 and Bace2 knockout zebrafish were generated using zinc finger nuclease-mediated genome editing. Bace1 mutants showed hypomyelination in the peripheral nervous system while Bace2 mutants showed anomalous migration of the melanocytes ${ }^{120}$. However, the Bace1/2 double knockout zebrafish did not display any enhancement in the mutant phenotypes, pointing out to the non redundant function of Bace1 and Bace2. Another $A \beta$ toxicity model was generated by using the mitfa (nacre) gene promoter for the expression of the $A \beta$ gene. The gene was chosen as it could produce a distinct disrupted pigmentation pattern in the larvae. However, the model did not turn out to be successful as the differential pigmentation pattern was evident in the adult fish, only at 16 months, by which time, the fish were infertile and too old for breeding ${ }^{121}$. Fluorescently labelled Tau transgenic zebrafish model of AD with a mutation Tau-P301L were also generated, which presented with the key pathological features of Tauopathy including neurofibrillary tangles, neuronal loss and cell death ${ }^{122}$. The zebrafish therefore harbour a huge resource of genetic information, which need to be manipulated to reveal the molecular details of AD.

\section{Disadvantages of zebrafish as an AD model}

There are several advantages in using zebrafish as a model system for studying AD and a few limitations in using them in translational neuroscience research. Pharmacological modifications in the fish are easily brought about by adding the desired chemicals in water. However, the quantification of chemical compound entering the fish is unpredictable, as substances can be absorbed randomly through the gills and skin of the fish owing to exposure of the whole body in the aqua medium ${ }^{123}$. Further, the fact that zebrafish-specific $A \beta$ peptide is yet to be elaborated remains a drawback. More research also needs to be performed to study whether the post translational processing of APP in humans is also prevalent in the zebrafish $^{124}$.

Zebrafish possesses a unique ability of regenerating neurons along their rostrocaudal brain axis throughout life unlike mammals. In an interesting observation, the researchers found that zebrafish microinjected with $A \beta_{1-42}$ peptide showed regeneration of neurons, specifically neural cell/progenitor cell proliferation and neurogenesis ${ }^{125}$. They studied the regenerative ability in old and young fish to understand the influence of aging and $A \beta$ deposition on neuroregeneration. They show that in neurodegeneration induced by $A \beta$, microglia get activated, to prevent synaptic degeneration and promote 
neurogenesis. Thus they establish a potential link between neurodegeneration, neuroinflammation and neurogenesis $^{125}$. This might pose a threat to the feasibility of the AD model but it definitely opens up a whole new world of research to delve into the molecular mechanisms of signalling pathways that could be active in playing a paramount role in the regeneration of neurons. This will surely pave the way for understanding the molecular programmes required for regeneration of the mammalian central nervous system.

\section{Real-time neurological imaging studies in zebrafish}

The zebrafish has a relatively simple nervous system, which allows imaging of neurons easily. This creates the possibility to visualise specific neuronal proteins of interest and thus provide a wonderful opportunity to study the neurological processes in detail ${ }^{49,126-130}$. Zebrafish larvae are small transparent vertebrates, which are highly suitable to confocal microscopy when labelled with dyes ${ }^{131}$. Thus, it facilitates studies regarding the in vivo physiological signalling processes in intact organ systems $^{132}$.

Real-time imaging using zebrafish has had a profound impact on the understanding of major physiological processes such as neurodegeneration (Table 1). Researchers could detect early pathological features like hyperphosphorylation and conformational changes of Tau within the first 2 days of embryonic development by real-time imaging using a stable transgenic zebrafish ${ }^{122}$. After a few days, the larvae developed substantial neurodegeneration displaying all pathological features including neurofibrillary tangles by 5 weeks of development. The pathological features develop much earlier in zebrafish as compared with the other available rodent models. As the zebrafish model provides the opportunity for easy manipulation and visualisation of the optically clear embryos ${ }^{122}$. Based on this, real-time imaging of microglial phagocytosis has enhanced the perception of microglia mediated neurodegeneration ${ }^{53}$. A group of scientists used laser imaging technique to measure the activity of nerve cells in zebrafish, propounding a novel association between Neurexin2 and spinal muscular atrophy; establishing neurexin 2 as a potential target for the treatment of $\mathrm{SMA}^{133}$. In vivo fragmentation of mitochondria was observed by real-time imaging when exposed to apoptosis-inducing agents in a mitochondrially targeted GFP-transgenic zebrafish ${ }^{134}$. Another group studied the effect of mitochondrial oxidation on vulnerability to axonal degeneration by time-lapse confocal imaging ${ }^{135}$. Detailed real-time imaging analysis of the timing of cell division in zebrafish embryo has also been analysed by real-time imaging ${ }^{136}$. Recently developed techniques like laser axotomy coupled with time-lapse imaging have revealed the role of extrinsic cell types in degeneration and regeneration in the zebrafish larvae ${ }^{137}$. Real-time imaging using zebrafish has therefore unearthed a vast amount of information in $\mathrm{AD}$, whereas the potential exists for a lot more to be brought to light.

\section{$\mathrm{Ca}^{2+}$ imaging in zebrafish}

Neuronal development of the larva and adult has been studied using the calcium imaging technique. These studies have presented us with a better understanding of the basic biological principles during development and adulthood of vertebrates ${ }^{138}$. Bulk loading approach involves the use of synthetic $\mathrm{Ca}^{2+}$ indicators to label cells within the tissue. This technique has been utilised to study the reticulospinal neurons or Mauthner cells in the larval zebrafish ${ }^{139,140}$. Microinjection of a chemical dye, Oregon Green BAPTA-1 results in specific labelling of neuronal cell bodies in the zebrafish brain ${ }^{140}$. Another group of researchers injected the calcium green dextran to study the Mauthner cell circuit in the living fish ${ }^{139}$. The next improvisation in this field is the use of aequorin, a bioluminescent photoprotein that emits light upon binding to $\mathrm{Ca}^{2+141}$. Aequorins have been successfully used for $\mathrm{Ca}^{2+}$ imaging in the zebrafish ${ }^{142,143}$. The subsequent development in this field is the use of in vivo two-photon $\mathrm{Ca}^{2+}$ imaging. Understanding of the functional topology of neural activity patterns has been possible using this technique ${ }^{144,145}$. Another recent development in this area is the use of genetically encoded calcium indicators such as cameleon. Their major advantage is the ability to monitor neuron activity in a non-invasive manner in the living zebrafish ${ }^{146}$. Calcium imaging has also provided insights into the cellular events that execute axonal dystrophy arising in neurodegeneration ${ }^{147,148}$. Thus the $\mathrm{Ca}^{2+}$ imaging technique has helped in understanding the functional role of neurons which would not have been possible by other approaches.

\section{D imaging in zebrafish}

The zebrafish is yet again adept for one of the most recent imaging techniques, which is the threedimensional reconstruction of images to produce a $3 \mathrm{D}$ volumetric representation of the specimen. It includes three-dimensional time-lapse imaging of embryos either by confocal or multiphoton laser scanning microscopy. This technique employs the use of varied signals for analysis of the image, including two-photon-excited fluorescence, second harmonic generation and third harmonic generation ${ }^{149}$. Selective plane illumination microscopy, also known as light sheet fluorescence microscopy is another technique used in $3 \mathrm{D}$ imaging ${ }^{150}$. Apart from this, researchers have also used fluorescent probes to construct 3D imaging in live zebrafish ${ }^{151}$. This serves for high-throughput imaging ensuring sufficient 
Table 1 Alzheimer's disease: insights revealed by real-time imaging in Zebrafish

\begin{tabular}{|c|c|c|}
\hline Paper & Findings & $\begin{array}{l}\text { References } \\
\text { (Pubmed ID) }\end{array}$ \\
\hline Plucinska G et al. 2012 & $\begin{array}{l}\text { Microtubule-affinity regulating kinase } 2 \text { (MARK-2), regulates axonal transport in a Tau-dependent } \\
\text { manner. }\end{array}$ & 23152604 \\
\hline Kim MJ et al. 2008 & $\begin{array}{l}\text { In vivo fragmentation of mitochondria upon exposure to the following apoptosis-inducing } \\
\text { drugs: valinomycin, carbonyl cyanide 4-(trifluoromethoxy) phenylhydrazone (FCCP) and } \\
\text { staurosporine. }\end{array}$ & 18778258 \\
\hline Leung LC et al. 2013 & Imaging zebrafish neural circuitry. & 23630470 \\
\hline Renninger SL et al. 2013 & Two-photon calcium imaging of neural population activity in zebrafish. & 23727462 \\
\hline Feierstein CE et al. 2015 & Functional mapping of circuits in behaving zebrafish. & 25433239 \\
\hline Ahrens MB et al. 2012 & $\begin{array}{l}\text { Brain-wide dynamics at single-cell resolution using two-photon calcium imaging during } \\
\text { behaviour. }\end{array}$ & 22622571 \\
\hline Aizenberg M et al. 2011 & $\begin{array}{l}\text { Conditioned stimulus and unconditioned stimulus activate different subsets of neurons in the } \\
\text { cerebellum, using calcium imaging in zebrafish. }\end{array}$ & 21677154 \\
\hline Panula P et al. 2006 & Analysis of modulatory neurotransmitter systems and behaviour in zebrafish. & 18248264 \\
\hline Moritz C et al. 2015 & $\sigma 1$ receptor modulates microglial responses in neurodegeneration. & 25666889 \\
\hline Casano AM et al. 2016 & $\begin{array}{l}\text { Role for developmental apoptosis in the long-term positioning of microglia in the zebrafish } \\
\text { brain. }\end{array}$ & 27425604 \\
\hline Paquet D et al. 2009 & Neuronal cell death induced by TAU was imaged by time-lapse microscopy in vivo. & 19363289 \\
\hline Peri F et al. 2008 & a1 subunit mediates fusion between phagosomes and lysosomes during phagocytosis. & 18510934 \\
\hline Kozawa S et al. 2016 & In vivo imaging and real-time prediction of cell division timing in developing zebrafish embryo. & 27597656 \\
\hline Ritter DA et al. 2001 & Predictions regarding varied behavioural roles for different classes of spinal interneurons. & 11698606 \\
\hline Gahtan E et al. 2002 & Widespread distribution of neural control systems in the zebrafish brain. & 11784774 \\
\hline Takahashi M et al. & $\begin{array}{l}\text { In vivo imaging of functional networks inhibitory in nature on the mauthner cell of larval } \\
\text { zebrafish. }\end{array}$ & 12019312 \\
\hline Creton R et al. 2000 & Requirement of apo-aequorin during embryonic development for calcium imaging? & 9502193 \\
\hline Higashijima S et al. 2003 & Use of cameleon for imaging neurons. & 12930818 \\
\hline Muto A et al. 2016 & Functional imaging of the brain under natural behavioural conditions. & 27464819 \\
\hline
\end{tabular}

reproducibility of observations. Vertebrate automated screening technology has been used to take multiple axial views of the zebrafish larvae. These were later reconstructed to produce 3D volumetric representation of the larvae and also its measurements, thus providing a more holistic view ${ }^{152}$. Extensive automated processing techniques have also been developed to analyse the complex images for easier comprehension ${ }^{153}$. 3D high resolution imaging is a rapidly developing technique but is accompanied by some technical issues like high expense, normalisation, artefact corrections and web-based publication of results among others. A recent discovery has addressed one such issue by coming up with a multiusage observation chamber called UniverSlide adapted for live $3 \mathrm{D}$ bio imaging of the zebrafish larvae ${ }^{154}$.

$3 \mathrm{D}$ imaging in zebrafish is a most recent technique and still rapidly evolving, which allows the visualisation of the whole organism, thus leading to an elaborate understanding of the in vivo scenario in the organism. It is therefore a highly promising technique that could produce a breakthrough in the field of zebrafish imaging and thus help it to stand out as a star model for future research.

\section{Neurospecific drug discovery using zebrafish model}

Several approaches have been made to effectuate the discovery of potential therapeutic compounds exploiting the optical clarity of the zebrafish embryos and larvae. Owing to the small size of the embryo and larvae, drug discovery in a high-throughput scale can be achieved using this model system ${ }^{155}$. Till date, very few studies involving neurological drug discovery have been performed in the zebrafish, most of the studies being 
performed outside the nervous system ${ }^{156-160}$. Evaluation of a number of psychoactive compounds have also been performed using zebrafish ${ }^{161}$. Although it has been found that both nicotine ${ }^{162}$ and ethanol ${ }^{163}$ affect the development of the nervous system, cocaine ${ }^{164,165}$, amphetamine $^{95}$, morphine ${ }^{166,167}$, ethanol ${ }^{168,169}$ and nicotine have been noted to elicit reward or anxiety-related behaviour in the zebrafish. Interestingly, nicotine has been reported to have cognition enhancing effects in a learning paradigm in zebrafish $^{170}$.

A group of researchers identified a small molecule called prostaglandin E2, which regulates hematopoietic stem cell homoeostasis ${ }^{171}$. Small molecules that could relieve cell cycle arrest ${ }^{172}$ and cardiovascular problems ${ }^{173}$ and also modulate the embryonic heart rate ${ }^{174}$ by suppressing mutations have also been screened using zebrafish model system. Most importantly, research shows that the effect of these drugs is similar in humans and in zebrafish $^{158,175}$, thus validating that zebrafish models for drug discovery have the potential to produce or identify therapeutic compounds suiting human conditions ${ }^{176,177}$.

Studies have also been performed to analyse the effect of several neuroactive compounds in the zebrafish adults, whereby addition of such compounds in the water of the fish tanks have been shown to differentially change their swimming pattern and diving behaviour. Several neuroactive compounds like piracetam, methylenedioxymethamphetamine, hallucinogenic agents like mescaline and phencyclidine, a nitroamine explosive 1,3,5-Trinitroperhydro-1,3,5-triazine, kynurenic acid, $\Delta^{9}$-tetrahydrocannabinol and heroin (diacetylmorphine) have been tested using zebrafish ${ }^{178-184}$. Rapid behaviour-based screening has also evolved as an inexpensive assay for identifying small neuroactive molecules ${ }^{130,185}$.

The blood-brain barrier (BBB) of the zebrafish has molecular and functional similarity to the higher vertebrates $^{186-188}$. Analysis performed using transmission electron microscopy, fluorescent markers, chromatography and tandem mass spectrometry have revealed that BBB in the zebrafish is both structurally and functionally similar to that of mammals. Its development starts by 3 $\mathrm{dpf}$ and continues upto $10 \mathrm{dpf}$ in the zebrafish larvae ${ }^{189}$. Another group reports the presence of tight junctions in the $\mathrm{BBB}$ as the brain endothelial cells show immunoreactivity to Claudin-5 and Zona Occludens- ${ }^{190}$. Recently a group of researchers suggested an orthotopic glioblastoma model of zebrafish, which could be used as an efficient assay system for visualising the BBB penetrating efficiency of anti-GBM drugs ${ }^{191}$. Given the feasibility of high-throughput screening and the advantage of similarity with mammals, it is reasonable to say that zebrafish offers an excellent opportunity for screening neurospecific compounds.

\section{Controversies around the use of zebrafish for research on $A D$}

$\mathrm{A} \beta$ plaques are most widely believed to be pivotal to the pathogenesis of $\mathrm{AD}^{32,192,193}$. They lead to synaptic dysfunction, disruption of neuronal connectivity and neuron death ${ }^{194-199}$. Interestingly, research in the zebrafish model of $\mathrm{AD}$ suggests that $\mathrm{A} \beta$ may also play a role in maintaining cerebrovascular functions ${ }^{97}$. They show that $A \beta$ deficiency leads to reduction in cerebrovascular branching and vessel length in the developing hind brain of zebrafish embryo. In corroboration to this, another group of researchers reported that $A \beta$ is involved in regulation of angiogenesis in the human umbilical cord vein and in the zebrafish hind brain ${ }^{96}$. This role of $\mathrm{A} \beta$ in the zebrafish stands in complete refutation to its functionality in the humans; wherein it causes cerebrovascular dysfunction, leading to cognitive defects ${ }^{200,201}$. One probable reason for this discrepancy could be the fact that $A \beta$ in the teleosts is different from the other vertebrate $A \beta$ including humans ${ }^{97}$. The group further explains why drugs targeting $A \beta$ production failed in recent clinical trials as the potential function of $A \beta$ in regulating angiogenesis could be interfering with the mechanism of action of the drug. Further research on the molecular mechanism of this functionality shall help understand the discrepancy bet$t^{2}{ }^{92}$. This also points out to the existence of other nonamyloid hypotheses (cholinergic hypothesis ${ }^{33}$, tangles hypothesis ${ }^{34}$, calcium hypothesis ${ }^{35}$ and mitochondrial hypothesis ${ }^{37}$ among others) in AD. Several zebrafish AD models have already been established with focus on Tauopathy ${ }^{102,122}$ and cholinergic hypothesis ${ }^{202}$ while better models exhibiting a combination of several pathologies still remain to be studied. Elaborate studies involving real-time imaging in the zebrafish model may unravel potential roles of these hypotheses in $\mathrm{AD}$ pathogenesis. With these controversies, zebrafish emerges to be even more interesting as a model system for neurodegeneration which needs further research. It also holds promise as a complete model for understanding $\mathrm{AD}$ and providing a platform for research on areas which have not been dealt with earlier but could prove to be beneficial in the field of drug development.

\section{Future of zebrafish as a model for AD}

In the present review, we aim to illustrate the eminent progress that zebrafish propounds in order to comprehend the pathological mechanisms of $\mathrm{AD}$. It can be envisaged that zebrafish model has emerged as an interesting tool for strategic study of $\mathrm{AD}^{203}$. The gap between drug discovery based on cellular models and pre clinical assays can be efficiently bridged by research using this model system. The zebrafish presents itself as the best candidate for high-throughput pharmacological screening 
Table 2 Link between neurodevelopment and neurodegeneration: scope for research in zebrafish

\begin{tabular}{|c|c|c|c|}
\hline Paper & Findings & Scope of research & $\begin{array}{l}\text { References } \\
\text { (Pubmed ID) }\end{array}$ \\
\hline $\begin{array}{l}\text { Liu N et al. } \\
2012\end{array}$ & $\begin{array}{l}\text { mir-34 regulates healthy aging and long-term brain } \\
\text { integrity in Drosophila. mir-34 mediates its function by } \\
\text { silencing its target E74A gene, which is required for brain } \\
\text { development but is harmful during aging. }\end{array}$ & $\begin{array}{l}\text { Exploring this micro RNA may provide an insight into } \\
\text { the aging process and disease susceptibility. }\end{array}$ & 22343898 \\
\hline $\begin{array}{l}\text { Boehm M } \\
\text { et al. } 2005\end{array}$ & $\begin{array}{l}\text { microRNA lin-4 and its target, the putative transcription } \\
\text { factor lin-14, control the timing of larval development and } \\
\text { also regulate life span in the adult Caenorhabditis elegans. }\end{array}$ & $\begin{array}{l}\text { To study the role of homologues of this microRNA to } \\
\text { understand processes responsible for determining life } \\
\text { span in vertebrates. }\end{array}$ & 16373574 \\
\hline $\begin{array}{l}\text { Huang } X \\
\text { et al. } 2011\end{array}$ & $\begin{array}{l}\text { In C. elegans, Zinc finger protein SEA-2 regulates larval } \\
\text { developmental timing by controlling the expression of } \\
\text { heterochronic gene lin- } 28 \text {. SEA-2 also regulates aging in a } \\
\text { DAF-16/FOXO-dependent manner. }\end{array}$ & $\begin{array}{l}\text { To identify the subset of genes that regulate aging in } \\
\text { adults and development in larval stages. }\end{array}$ & 21471153 \\
\hline $\begin{array}{l}\text { Glynn P et al. } \\
2000\end{array}$ & $\begin{array}{l}\text { Neuropathy target esterase (NTE) is an integral membrane } \\
\text { protein in vertebrate neurons maintains interactions } \\
\text { between neurons and glial cells during development. } \\
\text { Whereas it leads to disrupted calcium signalling and } \\
\text { elevated Calpain activity in neurodegeneration condition. }\end{array}$ & $\begin{array}{l}\text { To explore the mechanism by which NTE maintains } \\
\text { communication between neurons and glia to help } \\
\text { understand these interactions in the vertebrate } \\
\text { system. }\end{array}$ & 10759065 \\
\hline
\end{tabular}

of drugs before validating them in rodent models. Abundant research has already been performed to elaborate on the scope of zebrafish as a model to understand AD. However, arenas like the behaviour, physiology, neuroanatomical circuitry of the fish and the link between neurodevelopment and neurodegeneration (Table 2) still need to be better elucidated. A good AD transgenic model expressing both $A \beta$ and Tau pathologies is the current requirement. This will help in completing the puzzle of understanding $\mathrm{AD}$, of which some pieces are still lacking. We conclude that the zebrafish has already come a long way as a potential model in the field of neurodegeneration, whereas it continues to emerge as an attractive model system for future research in AD. It definitely possesses a vast potential to be capitalised upon for developing therapeutic interventions for AD.

\section{Acknowledgements}

This work is supported in part by the Col. Dr. Jeppiaar Post Doctoral Fellowship and Department of Biotechnology, Govt. of India. (No. BT/PR6765/NNT/28/618/ 2012).

\section{Conflict of interest}

The authors declare that they have no conflict of interest.

\section{Publisher's note}

Springer Nature remains neutral with regard to jurisdictional claims in published maps and institutional affiliations.

Received: 14 June 2018 Revised: 21 August 2018 Accepted: 23 August 2018 Published online: 03 October 2018
References

1. Newman, M., Ebrahimie, E. \& Lardelli, M. Using the zebrafish model for Alzheimer's disease research. Front. Genet. 5, 189 (2014).

2. Detrich, H. W. 3rd, Westerfield, M. \& Zon, L. I. Overview of the Zebrafish system. Methods Cell Biol. 59, 3-10 (1999).

3. Cooper, M. S., D'Amico, L. A. \& Henry, C. A. Analyzing morphogenetic cell behaviors in vitally stained zebrafish embryos. Methods Mol. Biol. 122, 185-204 (1999).

4. Cooper, M. S., D'Amico, L. A. \& Henry, C. A. Confocal microscopic analysis of morphogenetic movements. Methods Cell Biol. 59, 179-204 (1999).

5. Kimmel, C. B. Genetics and early development of zebrafish. Trends Genet. 5, 283-288 (1989).

6. Kimmel, C. B. \& Warga, R. M. Cell lineage and developmental potential of cells in the zebrafish embryo. Trends Genet. 4, 68-74 (1988).

7. Solnica-Krezel, L., Stemple, D. L. \& Driever, W. Transparent things: cell fates and cell movements during early embryogenesis of zebrafish. Bioessays 17, 931-939 (1995)

8. Spitsbergen, J. M. \& Kent, M. L. The state of the art of the zebrafish model for toxicology and toxicologic pathology research--advantages and current limitations. Toxicol. Pathol. 31, 62-87 (2003).

9. Rosemberg, D. B. et al. Behavioral effects of taurine pretreatment in zebrafish acutely exposed to ethanol. Neuropharmacology 63, 613-623 (2012).

10. Tran, S. \& Gerlai, R. Thirty-second net stressor task in adult zebrafish. Bio. Protoc. 5, e1413 (2015).

11. Hwang, W. Y. et al. Efficient genome editing in zebrafish using a CRISPR-Cas system. Nat. Biotechnol. 31, 227-229 (2013).

12. Hisano, Y., Ota, S. \& Kawahara, A. Genome editing using artificial site-specific nucleases in zebrafish. Dev. Growth Differ. 56, 26-33 (2014).

13. Schmid, B. \& Haass, C. Genomic editing opens new avenues for zebrafish as a model for neurodegeneration. J. Neurochem. 127, 461-470 (2013).

14. Ebrahimie, E., Fruzangohar, M., Moussavi Nik, S. H. \& Newman, M. Gene ontology-based analysis of zebrafish omics data using the web tool comparative gene ontology. Zebrafish 14, 492-494 (2017).

15. Cummings, J. L. Alzheimer's disease. N. Engl. J. Med. 351, 56-67 (2004).

16. Stefanacci, R. G. The costs of Alzheimer's disease and the value of effective therapies. Am. J. Manag. Care 17(Suppl 13), S356-S362 (2011).

17. Serrano-Pozo, A., Frosch, M. P., Masliah, E. \& Hyman, B. T. Neuropathological alterations in Alzheimer disease. Cold Spring Harb. Perspect. Med. 1, a006189 (2011). 
18. Voisin, T. \& Vellas, B. Diagnosis and treatment of patients with severe Alzheimer's disease. Drugs Aging 26, 135-144 (2009).

19. Blennow, K., de Leon, M. J. \& Zetterberg, H. Alzheimer's disease. Lancet 368, 387-403 (2006).

20. Regeur, L., Jensen, G. B., Pakkenberg, H., Evans, S. M. \& Pakkenberg, B. No global neocortical nerve cell loss in brains from patients with senile dementia of Alzheimer's type. Neurobiol. Aging 15, 347-352 (1994).

21. West, M. J., Coleman, P. D., Flood, D. G. \& Troncoso, J. C. Differences in the pattern of hippocampal neuronal loss in normal ageing and Alzheimer's disease. Lancet 344, 769-772 (1994).

22. Levy Nogueira, M. et al. Mechanical stress related to brain atrophy in Alzheimer's disease. Alzheimers Dement. 12, 11-20 (2016).

23. Dorszewska, J., Prendecki, M., Oczkowska, A., Dezor, M. \& Kozubski, W. Molecular basis of familial and sporadic Alzheimer's disease. Curr. Alzheimer Res. 13, 952-963 (2016)

24. Selkoe, D. J. \& Podlisny, M. B. Deciphering the genetic basis of Alzheimer's disease. Annu. Rev. Genomics Hum. Genet. 3, 67-99 (2002).

25. Bird, T. D. in GeneReviews ${ }^{\circledR}$ (eds M. P. Adam et al.) (University of Washington, Seattle, 1993-2018).

26. Kim, J., Basak, J. M. \& Holtzman, D. M. The role of apolipoprotein E in Alzheimer's disease. Neuron 63, 287-303 (2009).

27. Corder, E. H. et al. Gene dose of apolipoprotein E type 4 allele and the risk of Alzheimer's disease in late onset families. Science 261, 921-923 (1993).

28. Strittmatter, W. J. et al. Apolipoprotein E: high-avidity binding to betaamyloid and increased frequency of type 4 allele in late-onset familial Alzheimer disease. Proc. Natl Acad. Sci. USA 90, 1977-1981 (1993).

29. Hardy, J. A. \& Higgins, G. A. Alzheimer's disease: the amyloid cascade hypothesis. Science 256, 184-185 (1992).

30. Verdile, G. et al. The role of beta amyloid in Alzheimer's disease: still a cause of everything or the only one who got caught? Pharmacol. Res. 50, 397-409 (2004).

31. Karran, E. \& De Strooper, B. The amyloid cascade hypothesis: are we poised for success or failure. J. Neurochem. 139, 237-252 (2016).

32. Hardy, J. \& Selkoe, D. J. The amyloid hypothesis of Alzheimer's disease: progress and problems on the road to therapeutics. Science 297, 353-356 (2002).

33. Francis, P. T., Palmer, A. M., Snape, M. \& Wilcock, G. K. The cholinergic hypothesis of Alzheimer's disease: a review of progress. J. Neurol. Neurosurg. Psychiatry 66, 137-147 (1999).

34. Maccioni, R. B., Farias, G., Morales, I. \& Navarrete, L. The revitalized tau hypothesis on Alzheimer's disease. Arch. Med. Res. 41, 226-231 (2010).

35. Berridge, M. J. Calcium hypothesis of Alzheimer's disease. Pflug. Arch.: Eur. J. Physiol. 459, 441-449 (2010).

36. Alzheimer's Association Calcium Hypothesis. W. Calcium Hypothesis of Alzheimer's disease and brain aging: a framework for integrating new evidence into a comprehensive theory of pathogenesis. Alzheimers Dement. 13, 178-182 e117 (2017)

37. Swerdlow, R. H., Burns, J. M. \& Khan, S. M. The Alzheimer's disease mitochondrial cascade hypothesis. J. Alzheimers Dis. 20(Suppl 2), S265-S279 (2010).

38. Wullimann, M., Rupp, B. \& Reichert, H. Introduction: neuroanatomy for a neurogenetic model system. In: Neuroanatomy of the Zebrafish Brain. Ch. 1, 1-5 (Birkhäuser Basel, Switzerland, 1996).

39. Mueller, T. \& Wullimann, M. An evolutionary interpretation of teleostean forebrain anatomy. Brain Behav. Evol. 74, 30-42 (2009).

40. Wullimann, M., B. Rupp, D. \& Dr. H. Reichert, P. The brain of the zebrafish Danio rerio: an overview. In: Neuroanatomy of the Zebrafish Brain. Ch. 3, 7-17 (Birkhäuser Basel, Switzerland, 1996).

41. Rink, E. \& Wullimann, M. Connections of the ventral telencephalon (subpallium) in the zebrafish (Danio rerio). Brain Res. 1011, 206-20 (2004).

42. Mueller, T., Vernier, P. \& Wullimann, M. The adult central nervous cholinergic system of a neurogenetic model animal, the zebrafish Danio rerio. Brain Res. 1011,156-169 (2004).

43. Braford, M. R. Jr. Comparative aspects of forebrain organization in the rayfinned fishes: touchstones or not? Brain Behav. Evol. 46, 259-274 (1995).

44. Mueller, T., Dong, Z., Berberoglu, M. A. \& Guo, S. The dorsal pallium in zebrafish, Danio rerio (Cyprinidae, Teleostei). Brain Res. 1381, 95-105 (2011).

45. Northcutt, R. G. Connections of the lateral and medial divisions of the goldfish telencephalic pallium. J. Comp. Neurol. 494, 903-943 (2006).
46. Portavella, M., Vargas, J. P., Torres, B. \& Salas, C. The effects of telencephalic pallial lesions on spatial, temporal, and emotional learning in goldfish. Brain Res. Bull. 57, 397-399 (2002).

47. Rico, E. P. et al. Zebrafish neurotransmitter systems as potential pharmacological and toxicological targets. Neurotoxicol. Teratol. 33, 608-617 (2011).

48. Park, E., Lee, Y., Kim, Y. \& Lee, C. J. Cholinergic modulation of neural activity in the telencephalon of the zebrafish. Neurosci. Lett. 439, 79-83 (2008).

49. Panula, P. et al. Modulatory neurotransmitter systems and behavior: towards zebrafish models of neurodegenerative diseases. Zebrafish 3, 235-247 (2006).

50. Chen, Y. C., Priyadarshini, M. \& Panula, P. Complementary developmental expression of the two tyrosine hydroxylase transcripts in zebrafish. Histochem. Cell Biol. 132, 375-381 (2009).

51. Anichtchik, O., Sallinen, V., Peitsaro, N. \& Panula, P. Distinct structure and activity of monoamine oxidase in the brain of zebrafish (Danio rerio). J. Comp. Neurol. 498, 593-610 (2006).

52. Kawai, H., Arata, N. \& Nakayasu, H. Three-dimensional distribution of astrocytes in zebrafish spinal cord. Glia 36, 406-413 (2001).

53. Peri, F. \& Nusslein-Volhard, C. Live imaging of neuronal degradation by microglia reveals a role for v0-ATPase a1 in phagosomal fusion in vivo. Cell 133, 916-927 (2008)

54. Yoshida, M. \& Macklin, W. B. Oligodendrocyte development and myelination in GFP-transgenic zebrafish. J. Neurosci. Res. 81, 1-8 (2005).

55. Koulen, P., Janowitz, T., Johnston, L. D. \& Ehrlich, B. E. Conservation of localization patterns of $\mathrm{IP}(3)$ receptor type 1 in cerebellar Purkinje cells across vertebrate species. J. Neurosci. Res. 61, 493-499 (2000).

56. Avila, R. L., Tevlin, B. R., Lees, J. P. B., Inouye, H. \& Kirschner, D. A. Myelin structure and composition in zebrafish. Neurochem. Res. 32, 197-209 (2007).

57. Westerfield, M., McMurray, J. V. \& Eisen, J. S. Identified motoneurons and their innervation of axial muscles in the zebrafish. J. Neurosci. 6, 2267-2277 (1986).

58. Stil, A. \& Drapeau, P. Neuronal labeling patterns in the spinal cord of adult transgenic Zebrafish. Dev. Neurobiol. 76, 642-660 (2016).

59. Chong, M. \& Drapeau, P. Interaction between hind brain and spinal networks during the development of locomotion in zebrafish. Dev. Neurobiol. 67, 933-947 (2007).

60. Madgwick, A. et al. Neural differentiation modulates the vertebrate brain specific splicing program. PLOS. ONE 10, e0125998 (2015).

61. Gahtan, E., Tanger, P. \& Baier, H. Visual prey capture in larval zebrafish is controlled by identified reticulospinal neurons downstream of the tectum. J. Neurosci. 25, 9294-9303 (2005).

62. Del Bene, F. et al. Filtering of visual information in the tectum by an identified neural circuit. Science 330, 669-673 (2010).

63. Bianco, I. H., Kampff, A. R. \& Engert, F. Prey capture behavior evoked by simple visual stimuli in larval zebrafish. Front. Syst. Neurosci. 5, 101 (2011).

64. Valente, A., Huang, K. H., Portugues, R. \& Engert, F. Ontogeny of classical and operant learning behaviors in zebrafish. Learn. Mem. 19, 170-177 (2012).

65. Gleason, M. R. et al. The transmembrane inner ear (Tmie) protein is essential for normal hearing and balance in the zebrafish. Proc. Natl Acad. Sci. USA 106, 21347-21352 (2009).

66. Emran, F. et al. OFF ganglion cells cannot drive the optokinetic reflex in zebrafish. Proc. Natl Acad. Sci. USA 104, 19126-19131 (2007).

67. Low, S. E. et al. touche Is required for touch-evoked generator potentials within vertebrate sensory neurons. J. Neurosci. 30, 9359-9367 (2010).

68. Low, S. E. et al. TRPM7 is required within zebrafish sensory neurons for the activation of touch-evoked escape behaviors. J. Neurosci. 31, 11633-11644 (2011).

69. Low, S. E. et al. Touch responsiveness in zebrafish requires voltage-gated calcium channel 2.1b. J. Neurophysiol. 108, 148-159 (2012).

70. Speedie, N. \& Gerlai, R. Alarm substance induced behavioral responses in zebrafish (Danio rerio). Behav. Brain. Res. 188, 168-177 (2008).

71. Agetsuma, M. et al. The habenula is crucial for experience-dependent modification of fear responses in zebrafish. Nat. Neurosci. 13, 1354-1356 (2010).

72. Mathuru, A. S. et al. Chondroitin fragments are odorants that trigger fear behavior in fish. Curr. Biol. 22, 538-544 (2012).

73. Prober, D. A. et al. Zebrafish TRPA1 channels are required for chemosensation but not for thermosensation or mechanosensory hair cell function. J. Neurosci. 28, 10102-10110 (2008).

74. Lee, A. et al. The habenula prevents helpless behavior in larval zebrafish. Curr. Biol. 20, 2211-2216 (2010).

75. Darrow, K. O. \& Harris, W. A. Characterization and development of courtship in zebrafish, Danio rerio. Zebrafish 1, 40-45 (2004). 
76. Mahabir, S., Chatterjee, D., Buske, C. \& Gerlai, R. Maturation of shoaling in two zebrafish strains: a behavioral and neurochemical analysis. Behav. Brain. Res. 247, 1-8 (2013).

77. Qin, M., Wong, A., Seguin, D. \& Gerlai, R. Induction of social behavior in zebrafish: live versus computer animated fish as stimuli. Zebrafish 11, 185-197 (2014).

78. Stewart, A. et al. Modeling anxiety using adult zebrafish: a conceptual review. Neuropharmacology 62, 135-143 (2012).

79. Arganda, S., Perez-Escudero, A. \& de Polavieja, G. G. A common rule for decision making in animal collectives across species. Proc. Natl Acad. Sci. USA 109, 20508-20513 (2012)

80. Prober, D. A., Rihel, J., Onah, A. A., Sung, R. J. \& Schier, A. F. Hypocretin/orexin overexpression induces an insomnia-like phenotype in zebrafish. J. Neurosci. 26, 13400-13410 (2006).

81. Zhdanova, I. V. Sleep in zebrafish. Zebrafish 3, 215-226 (2006).

82. Yokogawa, T. et al. Characterization of sleep in zebrafish and insomnia in hypocretin receptor mutants. PLOS Biol. 5, e277 (2007).

83. Rihel, J. et al. Zebrafish behavioral profiling links drugs to biological targets and rest/wake regulation. Science 327, 348-351 (2010).

84. Zhdanova, I. V., Wang, S. Y., Leclair, O. U. \& Danilova, N. P. Melatonin promotes sleep-like state in zebrafish. Brain Res. 903, 263-268 (2001).

85. Witting, W., Kwa, I. H., Eikelenboom, P., Mirmiran, M. \& Swaab, D. F. Alterations in the circadian rest-activity rhythm in aging and Alzheimer's disease. Biol. Psychiatry 27, 563-572 (1990).

86. Skene, D. J. \& Swaab, D. F. Melatonin rhythmicity: effect of age and Alzheimer's disease. Exp. Gerontol. 38, 199-206 (2003).

87. Hatfield, C. F., Herbert, J., van Someren, E. J., Hodges, J. R. \& Hastings, M. H. Disrupted daily activity/rest cycles in relation to daily cortisol rhythms of home-dwelling patients with early Alzheimer's dementia. Brain 127 1061-1074 (2004).

88. Wu, Y. H. et al. Pineal clock gene oscillation is disturbed in Alzheimer's disease, due to functional disconnection from the "master clock". FASEB J. 20 1874-1876 (2006).

89. Hu, K., Van Someren, E. J., Shea, S. A. \& Scheer, F. A. Reduction of scale invariance of activity fluctuations with aging and Alzheimer's disease: Involvement of the circadian pacemaker. Proc. Natl Acad. Sci. USA 106, 2490-2494 (2009).

90. Coogan, A. N. et al. The circadian system in Alzheimer's disease: disturbances, mechanisms, and opportunities. Biol. Psychiatry 74, 333-339 (2013).

91. Cahill, G. M. Clock mechanisms in zebrafish. Cell Tissue Res. 309, 27-34 (2002).

92. Rawashdeh, O., de Borsetti, N. H., Roman, G. \& Cahill, G. M. Melatonin suppresses nighttime memory formation in zebrafish. Science 318, 1144-1146 (2007)

93. Cahill, G. M., Hurd, M. W. \& Batchelor, M. M. Circadian rhythmicity in the locomotor activity of larval zebrafish. Neuroreport 9, 3445-3449 (1998).

94. Cahill, G. M. Circadian regulation of melatonin production in cultured zebrafish pineal and retina. Brain Res. 708, 177-181 (1996).

95. Ninkovic, J. et al. Genetic identification of AChE as a positive modulator of addiction to the psychostimulant D-amphetamine in zebrafish. J. Neurobiol. 66, 463-475 (2006)

96. Cameron, D. J. et al. Alzheimer's-related peptide amyloid-beta plays a conserved role in angiogenesis. PLOS. ONE 7, e39598 (2012).

97. Luna, S., Cameron, D. J. \& Ethell, D. W. Amyloid-beta and APP deficiencies cause severe cerebrovascular defects: important work for an old villain. PLoS. ONE 8, e75052 (2013)

98. Donnini, S. et al. Abeta peptides accelerate the senescence of endothelial cells in vitro and in vivo, impairing angiogenesis. FASEB J. 24, 2385-2395 (2010).

99. Dujardin, S., Colin, M. \& Buee, L. Invited review: Animal models of tauopathies and their implications for research/translation into the clinic. Neuropathol. Appl. Neurobiol. 41, 59-80 (2015).

100. Bai, Q. \& Burton, E. A. Zebrafish models of tauopathy. Biochim. Biophys. Acta 1812, 353-363 (2011)

101. Tomasiewicz, H. G., Flaherty, D. B., Soria, J. P. \& Wood, J. G. Transgenic zebrafish model of neurodegeneration. J. Neurosci. Res. 70, 734-745 (2002).

102. Bai, Q., Garver, J. A., Hukriede, N. A. \& Burton, E. A. Generation of a transgenic zebrafish model of Tauopathy using a novel promoter element derived from the zebrafish eno2 gene. Nucleic Acids Res. 35, 6501-6516 (2007).

103. Best, J. D. et al. Non-associative learning in larval zebrafish. Neuropsychopharmacology 33, 1206-1215 (2008).
104. Nery, L. R. et al. Brain intraventricular injection of amyloid-beta in zebrafish embryo impairs cognition and increases tau phosphorylation, effects reversed by lithium. PLOS. ONE 9, e105862 (2014).

105. Chen, J. et al. Trimethyltin chloride (TMT) neurobehavioral toxicity in embryonic zebrafish. Neurotoxicol. Teratol. 33, 721-726 (2011).

106. Nada, S. E., Williams, F. E. \& Shah, Z. A. Development of a novel and robust pharmacological model of okadaic acid-induced Alzheimer's disease in zebrafish. CNS Neurol. Disord. Drug. Targets 15, 86-94 (2016).

107. He, X., Zhong, Z. M. \& Che, Y. [Locomotor activity and learning and memory abilities in Alzheimer's disease induced by aluminum in an acid environment in zebrafish]. Dongwuxue Yanjiu 33, 231-236 (2012).

108. Paquet, D., Schmid, B. \& Haass, C. Transgenic zebrafish as a novel animal model to study tauopathies and other neurodegenerative disorders in vivo. Neurodegener. Dis. 7, 99-102 (2010).

109. Joshi, P. Liang, J. O., DiMonte, K. Sullivan, J. \& Pimplikar, S. W. Amyloid precursor protein is required for convergent-extension movements during Zebrafish development. Dev. Biol. 335, 1-11 (2009).

110. Mullan, M. et al. A pathogenic mutation for probable Alzheimer's disease in the APP gene at the N-terminus of beta-amyloid. Nat. Genet. 1, 345-347 (1992).

111. Andersen, O. M. et al. Neuronal sorting protein-related receptor sorLA/LR11 regulates processing of the amyloid precursor protein. Proc. Natl Acad. Sci. USA 102, 13461-13466 (2005)

112. Rogaeva, E. et al. The neuronal sortilin-related receptor SORL1 is genetically associated with Alzheimer disease. Nat. Genet. 39, 168-177 (2007).

113. Leimer, $U$. et al. Zebrafish (Danio rerio) presenilin promotes aberrant amyloid beta-peptide production and requires a critical aspartate residue for its function in amyloidogenesis. Biochemistry 38, 13602-13609 (1999).

114. Nornes, S., Groth, C., Camp, E., Ey, P. \& Lardelli, M. Developmental control of Presenilin1 expression, endoproteolysis, and interaction in zebrafish embryos. Exp. Cell Res. 289, 124-132 (2003).

115. Campbell, W. A. et al. Zebrafish lacking Alzheimer presenilin enhancer 2 (Pen2) demonstrate excessive p53-dependent apoptosis and neuronal loss. J. Neurochem. 96, 1423-1440 (2006).

116. Nornes, S. et al. Interference with splicing of Presenilin transcripts has potent dominant negative effects on Presenilin activity. Hum. Mol. Genet. 17, 402-412 (2008).

117. Ebrahimie, E., Moussavi Nik, S. H., Newman, M., Van Der Hoek, M. \& Lardelli, M. The zebrafish equivalent of Alzheimer's dsease-associated PRESENILIN isoform PS2V regulates inflammatory and other responses to hypoxic stress. J. Alzheimers Dis. 52, 581-608 (2016).

118. Sundvik, M., Chen, Y. C. \& Panula, P. Presenilin1 regulates histamine neuron development and behavior in zebrafish, danio rerio. J. Neurosci. 33 1589-1597 (2013).

119. Nornes, S. et al. Independent and cooperative action of Psen 2 with Psen 1 in zebrafish embryos. Exp. Cell Res. 315, 2791-2801 (2009).

120. van Bebber, F., Hruscha, A., Willem, M., Schmid, B. \& Haass, C. Loss of Bace2 in zebrafish affects melanocyte migration and is distinct from Bace1 knock out phenotypes. J. Neurochem. 127, 471-481 (2013).

121. Newman, M. et al. A zebrafish melanophore model of amyloid beta toxicity Zebrafish 7, 155-159 (2010).

122. Paquet, D. et al. A zebrafish model of tauopathy allows in vivo imaging of neuronal cell death and drug evaluation. J. Clin. Invest. 119, 1382-1395 (2009).

123. Rubinstein, A. L. Zebrafish assays for drug toxicity screening. Expert Opin Drug. Metab. Toxicol. 2, 231-240 (2006).

124. $\mathrm{Xi}_{1}$ Y., Noble, S. \& Ekker, M. Modeling neurodegeneration in zebrafish. Curr. Neurol. Neurosci. Rep. 11, 274-282 (2011).

125. Bhattarai, P., Thomas, A. K., Zhang, Y. \& Kizil, C. The effects of aging on Amyloid-beta42-induced neurodegeneration and regeneration in adult zebrafish brain. Neurogenesis (Austin) 4, e1322666 (2017)

126. Bhushan, B., Nandhagopal, S., Rajesh Kannan, R. \& Gopinath, P. Biomimetic nanomaterials: development of protein coated nanoceria as a potential antioxidative nano-agent for the effective scavenging of reactive oxygen species in vitro and in zebrafish model. Colloids Surf. B Biointerfaces 146 375-386 (2016).

127. Bhushan, B., Gopal, N. S., Rajesh Kannan, R. \& Packirisamy, G. Therapeutic nanozyme: antioxidative and cytoprotective effects of nanoceria against hydrogen peroxide induced oxidative stress in fibroblast cells and in zebrafish. ChemistrySelect 1 2849-2856 (2016). 
128. Moritz, C., Berardi, F., Abate, C. \& Peri, F. Live imaging reveals a new role for the sigma-1 (sigma1) receptor in allowing microglia to leave brain injuries. Neurosci. Lett. 591, 13-18 (2015)

129. Casano, A. M., Albert, M. \& Peri, F. Developmental apoptosis mediates entry and positioning of microglia in the zebrafish brain. Cell Rep. 16, 897-906 (2016).

130. Rajesh Kannan, R. \& Gp Vincent, S. ELISA based quantification of Pax6 expression in the developing Zebrafish embryos. Ann. Neurosci. 22,171-175 (2015).

131. Ritter, D. A., Bhatt, D. H. \& Fetcho, J. R. In vivo imaging of zebrafish reveals differences in the spinal networks for escape and swimming movements. J. Neurosci. 21, 8956-8965 (2001).

132. Friedrich, R. W. \& Korsching, S. I. Combinatorial and chemotopic odorant coding in the zebrafish olfactory bulb visualized by optical imaging. Neuron 18, 737-752 (1997)

133. See, K. et al. SMN deficiency alters Nrxn2 expression and splicing in zebrafish and mouse models of spinal muscular atrophy. Hum. Mol. Genet. 23 1754-1770 (2014).

134. Kim, M. J., Kang, K. H., Kim, C. H. \& Choi, S. Y. Real-time imaging of mitochondria in transgenic zebrafish expressing mitochondrially targeted GFP. Biotechniques 45, 331-334 (2008).

135. O'Donnell, K. C., Vargas, M. E. \& Sagasti, A. WIdS and PGC-1alpha regulate mitochondrial transport and oxidation state after axonal injury. J. Neurosci. 33 14778-14790 (2013).

136. Kozawa, S. et al. Real-time prediction of cell division timing in developing zebrafish embryo. Sci. Rep. 6, 32962 (2016).

137. Villegas, R. et al. Dynamics of degeneration and regeneration in developing zebrafish peripheral axons reveals a requirement for extrinsic cell types. Neural Dev. 7, 19 (2012)

138. Kettunen, P. Calcium imaging in the zebrafish. Adv. Exp. Med. Biol. 740 1039-1071 (2012).

139. Takahashi, M., Narushima, M. \& Oda, Y. In vivo imaging of functional inhibitory networks on the mauthner cell of larval zebrafish. J. Neurosci. 22, 3929-3938 (2002).

140. Gahtan, E., Sankrithi, N., Campos, J. B. \& O'Malley, D. M. Evidence for a widespread brain stem escape network in larval zebrafish. J. Neurophysiol. 87, 608-614 (2002).

141. Shimomura, O., Inouye, S., Musicki, B. \& Kishi, Y. Recombinant aequorin and recombinant semi-synthetic aequorins. Cellular $\mathrm{Ca} 2+$ ion indicators. Biochem. J. 270, 309-312 (1990).

142. Creton, R., Steele, M. E. \& Jaffe, L. F. Expression of apo-aequorin during embryonic development; how much is needed for calcium imaging? Cell Calcium 22, 439-446 (1997)

143. Shimomura, O., Musicki, B., Kishi, Y. \& Inouye, S. Light-emitting properties of recombinant semi-synthetic aequorins and recombinant fluoresceinconjugated aequorin for measuring cellular calcium. Cell Calcium 14 373-378 (1993).

144. Wachowiak, M., Denk, W. \& Friedrich, R. W. Functional organization of sensory input to the olfactory bulb glomerulus analyzed by twophoton calcium imaging. Proc. Natl Acad. Sci. USA 101, 9097-9102 (2004).

145. Yaksi, E., Judkewitz, B. \& Friedrich, R. W. Topological reorganization of odor representations in the olfactory bulb. PLoS Biol. 5, e178 (2007).

146. Higashijima, S., Masino, M. A., Mandel, G. \& Fetcho, J. R. Imaging neuronal activity during zebrafish behavior with a genetically encoded calcium indicator. J. Neurophysiol. 90, 3986-3997 (2003).

147. Vargas, M. E., Yamagishi, Y., Tessier-Lavigne, M. \& Sagasti, A. Live imaging of calcium dynamics during axon degeneration reveals two functionally distinct phases of calcium influx. J. Neurosci. 35, 15026-15038 (2015).

148. O'Donnell, K. C. et al. Axon degeneration and PGC-1alpha-mediated protection in a zebrafish model of alpha-synuclein toxicity. Dis. Models \& Mech. 7, 571-582 (2014).

149. Luengo-Oroz, M. A., Ledesma-Carbayo, M. J., Peyrieras, N. \& Santos, A. Image analysis for understanding embryo development: a bridge from microscopy to biological insights. Curr. Opin. Genet. Dev. 21, 630-637 (2011).

150. Keller, P. J., Schmidt, A. D., Wittbrodt, J. \& Stelzer, E. H. Reconstruction of zebrafish early embryonic development by scanned light sheet microscopy. Science 322, 1065-1069 (2008).

151. Hammers, M. D. et al. A bright fluorescent probe for $\mathrm{H} 2 \mathrm{~S}$ enables analyteresponsive, 3D imaging in live zebrafish using light sheet fluorescence microscopy. J. Am. Chem. Soc. 137, 10216-10223 (2015).
152. Guo, Y., Veneman, W. J., Spaink, H. P. \& Verbeek, F. J. Three-dimensional reconstruction and measurements of zebrafish larvae from high-throughput axial-view in vivo imaging. Biomed. Opt. Express 8, 2611-2634 (2017).

153. Mikut, R. et al. Automated processing of zebrafish imaging data: a survey. Zebrafish 10, 401-421 (2013).

154. Alessandri, K. et al. All-in-one 3D printed microscopy chamber for multidimensional imaging, the UniverSlide. Sci. Rep. 7, 42378 (2017).

155. Lessman, C. A. The developing zebrafish (Danio rerio): a vertebrate model for high-throughput screening of chemical libraries. Birth defects research. Birth Defects Res. C Embryo Today.: Rev. 93, 268-280 (2011).

156. Guo, S. Using zebrafish to assess the impact of drugs on neural development and function. Expert Opin. Drug Discov. 4, 715-726 (2009).

157. Scalzo, F. M. \& Levin, E. D. The use of zebrafish (Danio rerio) as a model system in neurobehavioral toxicology. Neurotoxicol. Teratol. 26, 707-708 (2004).

158. Parng, C., Roy, N. M., Ton, C., Lin, Y. \& McGrath, P. Neurotoxicity assessment using zebrafish. J. Pharmacol. Toxicol. Methods 55, 103-112 (2007).

159. Linney, E., Upchurch, L. \& Donerly, S. Zebrafish as a neurotoxicological model. Neurotoxicol. Teratol. 26, 709-718 (2004).

160. Parng, C., Ton, C., Lin, Y. X., Roy, N. M. \& McGrath, P. A zebrafish assay for identifying neuroprotectants in vivo. Neurotoxicol. Teratol. 28, 509-516 (2006).

161. Pitchai, A., Gnana, S., Vincent, P., Rajaretinam \& Rajesh Kannan, R. HPLC-PDA isolation and LC-MS/MS detection of an acetylcholinesterase inhibitory flavonoid from Tephrosia purpurea (L.) Pers. in zebrafish brain. Indian J Biochem. Biophys. 53,104-11 (2016).

162. Menelaou, E. \& Svoboda, K. R. Secondary motoneurons in juvenile and adult zebrafish: axonal pathfinding errors caused by embryonic nicotine exposure. J. Comp. Neurol. 512, 305-322 (2009).

163. Bilotta, J., Barnett, J. A., Hancock, L. \& Saszik, S. Ethanol exposure alters zebrafish development: a novel model of fetal alcohol syndrome. Neurotoxicol. Teratol. 26, 737-743 (2004).

164. Darland, T. \& Dowling, J. E. Behavioral screening for cocaine sensitivity in mutagenized zebrafish. Proc. Natl Acad. Sci. USA 98, 11691-11696 (2001).

165. Lopez-Patino, M. A., Yu, L., Cabral, H. \& Zhdanova, I. V. Anxiogenic effects of cocaine withdrawal in zebrafish. Physiol. Behav. 93, 160-171 (2008).

166. Lau, B., Bretaud, S., Huang, Y., Lin, E. \& Guo, S. Dissociation of food and opiate preference by a genetic mutation in zebrafish. Genes. Brain. Behav. 5, 497-505 (2006).

167. Bretaud, S. et al. A choice behavior for morphine reveals experiencedependent drug preference and underlying neural substrates in developing larval zebrafish. Neuroscience 146, 1109-1116 (2007).

168. Gerlai, R., Lahav, M., Guo, S. \& Rosenthal, A. Drinks like a fish: zebra fish (Danio rerio) as a behavior genetic model to study alcohol effects. Pharmacol. Biochem. Behav. 67, 773-782 (2000).

169. Lockwood, B., Bjerke, S., Kobayashi, K. \& Guo, S. Acute effects of alcohol on larval zebrafish: a genetic system for large-scale screening. Pharmacol. Biochem. Behav. 77, 647-654 (2004).

170. Levin, E. D., Limpuangthip, J., Rachakonda, T. \& Peterson, M. Timing of nicotine effects on learning in zebrafish. Psychopharmacol. (Berl.) 184 547-552 (2006).

171. North, T. E. et al. Prostaglandin E2 regulates vertebrate haematopoietic stem cell homeostasis. Nature 447, 1007-1011 (2007).

172. Stern, H. M. et al. Small molecules that delay S phase suppress a zebrafish bmyb mutant. Nat. Chem. Biol. 1, 366-370 (2005).

173. Peterson, R. T. et al. Chemical suppression of a genetic mutation in a zebrafish model of aortic coarctation. Nat. Biotechnol. 22, 595-599 (2004).

174. Burns, C. G. et al. High-throughput assay for small molecules that modulate zebrafish embryonic heart rate. Nat. Chem. Biol. 1, 263-264 (2005).

175. Ton, C., Lin, Y. \& Willett, C. Zebrafish as a model for developmental neurotoxicity testing. Birth. Defects Res. A. Clin. Mol. Teratol. 76, 553-567 (2006).

176. Langheinrich, U. Zebrafish: a new model on the pharmaceutical catwalk. Bioessays 25, 904-912 (2003).

177. Milan, D. J., Peterson, T. A., Ruskin, J. N., Peterson, R. T. \& MacRae, C. A. Drugs that induce repolarization abnormalities cause bradycardia in zebrafish. Circulation 107, 1355-1358 (2003).

178. Cachat, J. et al. Three-dimensional neurophenotyping of adult zebrafish behavior. PLOS. ONE 6, e17597 (2011).

179. Grossman, L. et al. Effects of piracetam on behavior and memory in adult zebrafish. Brain Res. Bull. 85, 58-63 (2011).

180. Stewart, A. et al. Behavioral effects of MDMA ('ecstasy') on adult zebrafish. Behav. Pharmacol. 22, 275-280 (2011). 
181. Kyzar, E. J. et al. Effects of hallucinogenic agents mescaline and phencyclidine on zebrafish behavior and physiology. Prog. Neuropsychopharmacol. Biol. Psychiatry 37, 194-202 (2012).

182. Williams, L. R. et al. Behavioral and physiological effects of RDX on adult zebrafish. Comp. Biochem. Physiol. C. Toxicol. Pharmacol. 155, 33-38 (2012).

183. Robinson, K. S. et al. Psychopharmacological effects of acute exposure to kynurenic acid (KYNA) in zebrafish. Pharmacol. Biochem. Behav. 108, 54-60 (2013).

184. Bruni, G., Lakhani, P. \& Kokel, D. Discovering novel neuroactive drugs through high-throughput behavior-based chemical screening in the zebrafish. Front. Pharmacol. 5, 153 (2014).

185. Rajaretinam, R. K. \& Samuel Gnana, P. V. Rapid neurobehavioural analysis based on the effects of an acetylcholinesterase inhibitor from Tephrosia purpurea in Zebrafish. Ann. Neurosci. 19, 8-13 (2012).

186. Annilo, T. et al. Evolution of the vertebrate $A B C$ gene family: analysis of gene birth and death. Genomics 88, 1-11 (2006).

187. Fischer, S. et al. Abcb4 acts as multixenobiotic transporter and active barrier against chemical uptake in zebrafish (Danio rerio) embryos. BMC Biol. 11, 69 (2013).

188. Long, Y., Li, Q. \& Cui, Z. Molecular analysis and heavy metal detoxification of ABCC1/MRP1 in zebrafish. Mol. Biol. Rep. 38, 1703-1711 (2011).

189. Fleming, A., Diekmann, H. \& Goldsmith, P. Functional characterisation of the maturation of the blood-brain barrier in larval zebrafish. PLOS. ONE 8, e77548 (2013).

190. Jeong, J. Y. et al. Functional and developmental analysis of the blood-brain barrier in zebrafish. Brain Res. Bull. 75, 619-628 (2008).

191. Zeng, A. et al. Identify a blood-brain barrier penetrating drug-TNB using zebrafish orthotopic globlastoma xenograft model. Sci. Rep. 7, 14372 (2017)

192. Scheuner, D. et al. Secreted amyloid beta-protein similar to that in the senile plaques of Alzheimer's disease is increased in vivo by the presenilin 1 and 2 and APP mutations linked to familial Alzheimer's disease. Nat. Med. 2, 864-870 (1996).

193. Murphy, M. P. \& LeVine, H. 3rd Alzheimer's disease and the amyloid-beta peptide. J. Alzheimers Dis. 19, 311-323 (2010)

194. Carter, J. \& Lippa, C. F. Beta-amyloid, neuronal death and Alzheimer's disease. Curr. Mol. Med. 1, 733-737 (2001)

195. Viola, K. L. \& Klein, W. L. Amyloid beta oligomers in Alzheimer's disease pathogenesis, treatment, and diagnosis. Acta Neuropathol. 129, 183-206 (2015).

196. Hardy, J. Alzheimer's disease: the amyloid cascade hypothesis: an update and reappraisal. J. Alzheimers Dis. 9, 151-153 (2006).

197. Palop, J. J. \& Mucke, L. Amyloid-beta-induced neuronal dysfunction in Alzheimer's disease: from synapses toward neural networks. Nat. Neurosci. 13 812-818 (2010).

198. Reddy, P. H. \& Beal, M. F. Amyloid beta, mitochondrial dysfunction and synaptic damage: implications for cognitive decline in aging and Alzheimer's disease. Trends Mol. Med. 14, 45-53 (2008).

199. Bayer, T. A. \& Wirths, O. Intracellular accumulation of amyloid-Beta - a predictor for synaptic dysfunction and neuron loss in Alzheimer's disease. Front. Aging Neurosci. 2, 8 (2010).

200. Qi, X. M. \& Ma, J. F. The role of amyloid beta clearance in cerebral amyloid angiopathy: more potential therapeutic targets. Transl. Neurodegener. 6, 22 (2017)

201. Smith, E. E. \& Greenberg, S. M. Beta-amyloid, blood vessels, and brain function. Stroke 40, 2601-2606 (2009).

202. Mueller, T., Vernier, P. \& Wullimann, M. F. The adult central nervous cholinergic system of a neurogenetic model animal, the zebrafish Danio rerio. Brain Res. 1011, 156-169 (2004).

203. Newman, M., Verdile, G., Martins, R. N. \& Lardelli, M. Zebrafish as a tool in Alzheimer's disease research. Biochim. Biophys. Acta 1812, 346-352 (2011). 